\title{
CARTOGRAFANDO CURRÍCULOS NA EDUCAÇÃO DE SURDOS: SABERES E PRÁTICAS DOCENTES ENTRE-DIFERENÇAS
}

\author{
Liliane Ferrari Giordani ${ }^{1}$ \\ Daniele Noal Gai ${ }^{2}$ \\ Cássia Lobato Marins ${ }^{3}$
}

\section{Resumo}

Este texto foi construído a partir da descrição de alguns currículos produzidos ao longo de encontros de formação de professores e gestores em escola de surdos da rede municipal de ensino de Porto Alegre. Com proposição de Atelier pedagógico, os encontros de formação produziram movimentos entre os professores, tanto na discussão sobre a aprendizagem de alunos surdos com ou sem deficiência. Foi possível propor tarefas, experimentações, conversas, visualizações que afirmam os diferentes tempos de multiconexão, de transinteração, de cultura visual. Os ateliers serviram para que afirmássemos uma cultura visual bilíngue entre-diferenças, com a defesa plena de direito à escola e às suas ensinagens por parte de todos os alunos surdos. A escrita que apresentamos aqui é resultado das análises realizadas a partir das reuniões de formação de professores e a experimentação de currículos. Estes materiais compõem parte das atividades da pesquisa "Cartografando a escolarização de alunos surdos com deficiência: diferentes aprendizagens e diferentes

\footnotetext{
${ }^{1}$ Professora do Departamento de Estudos Especializados da Faculdade de Educação da UFRGS. Doutora em Educação pelo PPGEdu/UFRGS. Faculdade de Educação - Prédio 12201/sala 918 - Av. Paulo Gama, s/n CEP 90046-900. Endereço eletrônico: liliane.giordani@ ufrgs.br

${ }^{2}$ Daniele Noal Gai, Professora do Departamento de Estudos Especializados da Faculdade de Educação da UFRGS. Doutoranda em Educação do PPGEdu/UFRGS. Faculdade de Educação - Prédio 12201/sala 918 - Av. Paulo Gama, s/n CEP 90046-900. Endereço eletrônico: daninoal@ yahoo.com.br

${ }^{3}$ Cássia Lobato Marins, Professora de LIBRAS da Universidade Federal do Rio Grande (FURG). Mestre em Educação pelo PPGEdu/UFRGS. Instittuto de Letras e Artes - FURG, Avenida Itália, km 8 ampus Carreiros CEP 96201-900. Endereço eletrônico: kk.marins@gmail.com
} 
saberes", coordenada pelas professoras Daniele Noal Gai e Liliane Ferrari Giordani e da pesquisa "Processos de Construção e Desenvolvimento de Currículos para Surdos com Deficiência em uma Escola Bilíngue para Surdos”, desenvolvido pela mestranda Cássia Lobato Marins. Ao longo deste texto nos dedicaremos a pensar nas construções coletivas para um currículo de aprendizagens em uma escola que se propõem bilíngue, uma vez que descreveremos ações que afirmam a escolarização e aprendizagem de alunos surdos com deficiência promovida em meio a uma cultura visual.

Palavras chaves: Educação de Surdos; Currículo; Cartografia; Deficiência

\section{IMERSÃO NO CONTEXTO DE PESQUISA: A ESCOLA E NOSSOS ENCONTROS DE PESQUISA E EXPERIMENTAÇÃO}

As pesquisas que alimentam este artigo foram realizadas em um contexto de escola bilíngue municipal para surdos de Porto Alegre/RS. A escola foi inaugurada em 2008 em um espaço provisório, e em 2012 mudou para o endereço atual, um lugar onde há um pátio com árvores e horta. As salas de aulas são bem amplas, com sala de recursos multifuncional e materiais para atendimento a alunos com deficiência visual, como a lupa, e quando necessário são feitos materiais ampliados, por exemplo, jogos com figura-fundo. Há acessibilidade arquitetônica com rampas de acesso no corredor, rampas de acesso às salas de aula, banheiros adaptados, sinal luminoso nas salas de aula. Conta com os dois professores especializados em AEE (Atendimento Educacional Especializado), que atuam na sala multifuncional, mas também vários outros professores possuem a formação em AEE. Isto é importante para atender as crianças surdas com deficiência, que precisam de algum tipo de apoio pedagógico para garantir o acesso dos alunos à educação.

No gráfico abaixo é possível visualizar o número de matrículas dos alunos surdos com deficiência. Entre os anos 2008 e 2013, há um aumento de matrículas que acompanha o percentual de alunos surdos com deficiências na escola. 


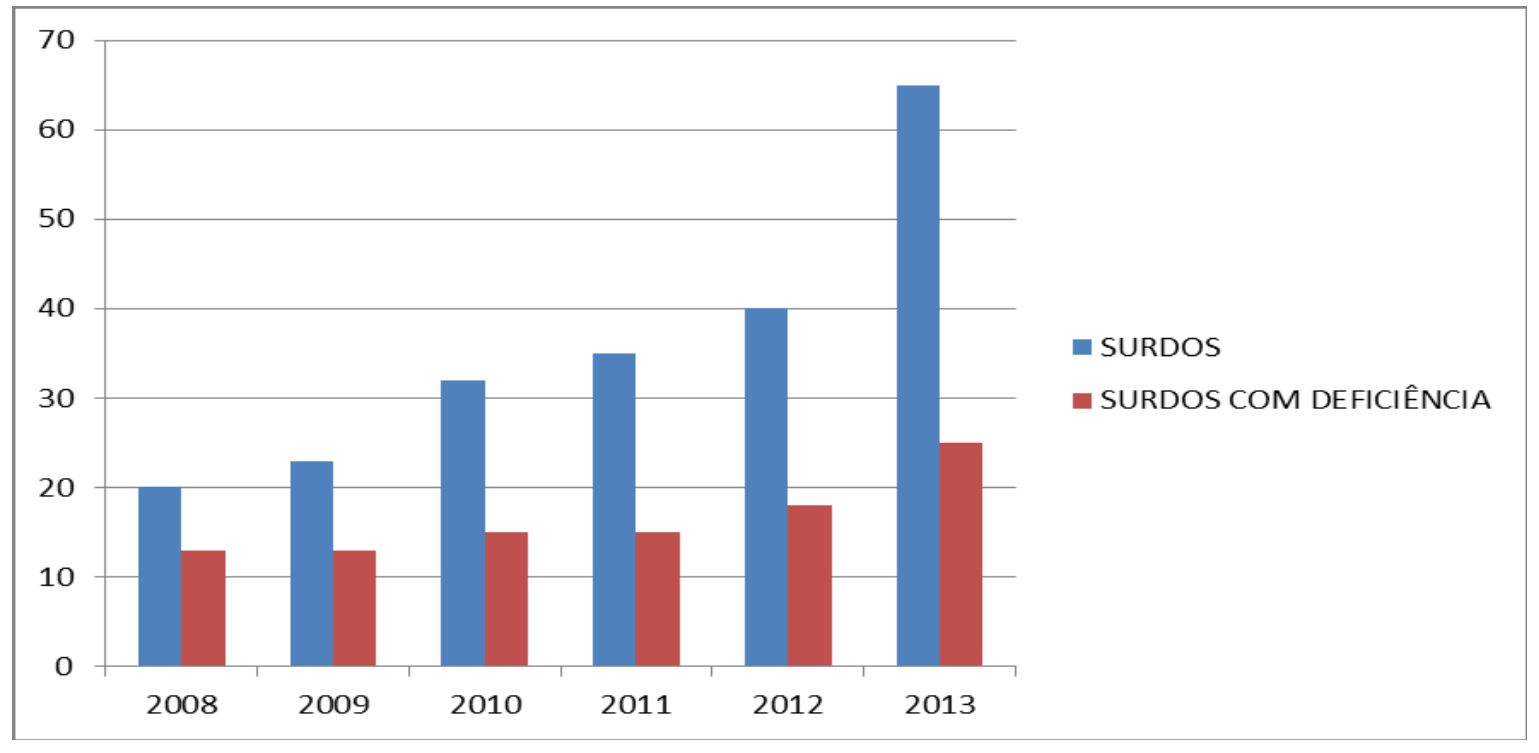

Fonte: Informações recebidas da secretaria da escola participante da pesquisa

No AEE, para cada aluno surdo com deficiência, é elaborado um Plano de Desenvolvimento Individual (PDI) onde constam os dados do aluno, um histórico da sua vida pessoal e familiar, detalhes do início da sua vida escolar, razões da surdez, medicações, atendimentos extraclasse, bem como alguns indicativos de como acontece a aprendizagem. Esse plano é feito através da ficha preenchida pelo professor da sala multifuncional, em parceria com a coordenação pedagógica e demais professores que atuam com o aluno em sala de aula.

A escola trabalha com uma proposta de Ciclos de Formação. A Secretaria Municipal de Educação do Município de Porto Alegre, no ano de 1999, apresentou como proposta político-educacional para organização do ensino e dos espaços-tempos da escola, a estruturação por Ciclos. Segundo esse documento, organizado pela Secretaria, os Ciclos e os conjuntos de providências e mudanças que acompanham sua implementação visam "romper com a seletividade e com a exclusão social à medida que propicia um ensino de melhor qualidade a essas crianças e jovens, majoritariamente pobres, que frequentam a escola pública e habitam em suas proximidades". (SMED, 1999, p. 12).

Em função das diferenças existentes entre os alunos, a proposta prevê Turmas de Progressão em todos os Ciclos, visando atender os educandos com defasagem entre sua faixa etária e a escolaridade, e servem para proceder à adaptação de estudos de educandos provenientes de outras escolas ou daqueles que não possuírem escolaridade nenhuma. 
Nessa perspectiva, a escola bilíngue pesquisada não segue rigidamente a faixa etária de cada Ciclo, considerando que muitos surdos chegam tardiamente na escola e sem uma aquisição de língua efetiva. Dessa forma, os surdos são organizados nos Ciclos levando em consideração o seu desenvolvimento linguístico e cognitivo. Também são utilizadas as Turmas de Progressão para promover o aprendizado mais rápido de alguns alunos, a fim de que passem de um Ciclo para outro mais adequado a eles.

\section{IMERSÃO EM AÇÕES DA PESQUISA E O MÉTODO CARTOGRÁFICO}

Organizamos cartograficamente o projeto, os temas, as provocações e as proposições da pesquisa na articulação presente com o cotidiano da escola e entregando aos atores - alunos e professores - a promoção dos dados da pesquisa, estando nós imbricados e misturados como pesquisadores nas cenas compartilhadas nos registros das falas, anotações, filmagens e fotografias. Compreendemos que a cartografia vem pelo meio -- busca no miúdo da pesquisa, naquilo que tem perspectiva simples, no que é muito caseiro na pesquisa -- as suas formas de conteúdo e expressão. Foi justamente nisso que interferimos: no que era caseiro e, justamente por isso, potente naquela escola.

O método cartográfico tomou rumos de experimentação na educação e vem produzindo efeitos diferentes daqueles que se espera previamente ao adentrar a pesquisa em educação. Este método não é prescritivo, tampouco segue um roteiro pré-definido de observação, análises e inferências. Trata-se de um movimento processual, de um envolvimento co-relacional, cooperativo e co-lateral, de construção de mapas, de esquemas, de observações, de anotações, de interferências e de inferências que se entrecruzam em meio à pesquisa.

É importante destacar que a cartografia vem sendo utilizada em pesquisas interessadas pelo estudo da subjetividade. Configura-se como um método cuja definição de passos fixos, engessados, estabelecidos a priori, é posta sob suspeita, seu fazer se faz por desfazer, por uma espécie de disposição de não estar pronto. 
Para que se efetivem os processos de reapropriação da subjetividade (...) até de crianças que se recusam a aceitar o sistema de educação e de vida que lhes é proposto, eles devem criar seus próprios modos de referência, suas próprias cartografias, devem inventar sua práxis de modo a fazer brechas no sistema de subjetividade dominante. (...) Em qualquer escala que essas lutas se expressem ou se agenciem, elas têm um alcance político (GUATTARI, 2005, p. 58-59).

O cartógrafo usa aquilo que tem em mãos, não se prepara anteriormente, pois quer dar vazão ao inusitado, ao acaso, ao que não estava previsto, ao novo, aos instantes. Parece-nos que a cartografia permite ver o contemporâneo de nossos dias. Uma cartografia do contemporâneo da vida. Assim fomos produzindo os dados de nossas pesquisas, absolutamente abertas ao inesperado. Os registros/arquivos/mapas foram produzidos nos encontros do projeto de extensão "Atelier Pedagógico" e nas realizações das atividades de intervenção, que foram propostas para os professores de modo que poderiam desenvolver junto a seus alunos, e, posteriormente, colocar em discussão os seus próprios resultados, as suas próprias experimentações pedagógicas. Um dos procedimentos, então, que se assumiu nesta pesquisa, para a cartografia de um currículo potente para invenções e aprendizagens, é a proposição de Ateliers.

Os ateliers pedagógicos intencionavam reunir diferentes informações e produzir uma diversidade de conhecimentos para, através da formação continuada de professores, auxiliar na construção de mecanismos que viabilizassem um currículo que potencializasse outras aprendizagens e outros tempos. Diferentes temas forma propostos em encontro de formações de professores: da problematização da não aprendizagem, das artes, da invenção, do brincar, da brincadeira e do brinquedo, de estudos sobre a deficiência intelectual e os transtornos globais do desenvolvimento, da vida adulta, da diferença, da educação bilíngue, da língua.

$\mathrm{Na}$ pesquisa cartográfica se cartografa o atual ou se atualiza radicalmente o vivido. A cartografia dá a ver o vivido, o vivo, a vida. Saber sobre cartografia, de modo a vivê-la na pesquisa, no estilo do texto, na forma de catar os dados, no jeito de apresentar o trabalho de pesquisa, nos modos de perceber as subjetividades coletivas, sabe-se, ainda são métodos nada tradicionais. Para quem se utiliza da cartografia, qualquer informação é relevante, é singular, é digna de análise, é autêntica, é apropriada.

Cartografias possíveis: as informações que chegam por meio do olhar, da conversação, dos encontros, de oficinas, de estudos, produzem no pesquisador a cartografia. O método não vem antes. A disposição e a preparação do cartógrafo passam pela experimentação. 
Cartografa aquele que faz aberturas a encontros inusitados. Aquele que faz cartografia se propõe a exposição, está exposto ao sol, ao tempo, e, por vezes, prefere sair de mãos dados na chuva do que de guarda-chuvas. Em pesquisa sempre há um intervalo entre o previsto, o tema de pesquisa, a ida a campo, a experiência efetiva da pesquisa, porém, nada disso é passível de separação.

A pesquisa se deu no processo, em contato com suas informações e informantes, como cartógrafos (ou intencionando ser um) nos fizemos pesquisadores em meio ao vivido na pesquisa, durante a pesquisa, quando se pesquisa. Neste sentido, nossa investigação não poderá ser generalizada, não sendo passível de comparações. Pois, na cartografia o conhecido, o visto, o que o olho registra, o que o papel resguarda --serve à pesquisa singularmente, localmente ou por hibridação. Num movimento cartográfico não se desvela, revela ou encontram-se causas. Num movimento de pesquisa cartográfico tudo serve à relatoria, às inferências, à invenção, às suposições, a um relicário -- daquela pesquisa frente aquele lócus.

Por dentro desta cartografia fizemos diferentes proposições de estudos de currículo, durante um ano, em uma escola da rede municipal de ensino de Porto Alegre. A escola bilíngue recebeu o projeto quinzenalmente, com encontros de pelo menos duas horas, no horário posterior àquele destinado à formação de seus professores. Um grupo de professores e gestores afinados com cada canto, com cada sala, com cada material, com cada bolo, com cada suco, com todos os aspectos daquele coletivo. A convivência não era absolutamente harmoniosa, nem esperamos tal homogeneidade nas relações profissionais, porém, destaca-se que havia um convívio cuidadoso e um convite sempre sério e receptivo para quem ali estava e aos que chegavam. Seguem nossos apontamentos de currículo pelo Atelier Pedagógico.

\section{ATELIER PEDAGÓGICO: PROFESSORES, ESCOLA E CURRÍCULOS EM MOVIMENTO}

Traçar um campo problemático enquanto cartógrafo significa problematizar as formas cognitivas do próprio pesquisador em sua relação junto ao campo ao qual se dedica. Assim, exige dele uma permanente modulação do problema, uma postura de abertura às forças que 
forçam a pensar, como uma sintonia com a dimensão da primeira regra do método intuitivo: reconciliar verdade e criação no nível dos problemas.

Tal pista põe em evidência a importância de que, em um trabalho de pesquisa e extensão, o pesquisador extensionista venha a se conduzir na direção de resoluções inventivas, que o forçam a traçar novos problemas, em uma inconformidade incessante que lhe permite não ceder às seduções das respostas apaziguadoras ligadas ao plano da recognição. Em lugar disso, o cartógrafo produz vitalidade às forças que dão existência às coisas, produzindo material de pesquisa no momento mesmo em que problematiza o campo (GALLI, 2012, p. 34).

Orientamo-nos em Gilles Deleuze (2006) no que se refere à cartografia e a aprendizagem, especialmente quando destaca a arte como destino inconsciente do aprendiz. A arte é o que resiste: ela resiste à morte, à servidão, à infâmia, à vergonha, aos abomináveis sofrimentos, ao limbo, às marcas de incapacidade, às marcas de não aprendizagem. Entendese que não dispõe de melhor aprendizado aquele que toca repetindo a música sempre da mesma forma, mas aquele que é capaz de interpretá-la, ou seja, aquele que, em suas repetições, é capaz do maior número de variações. Aprender é experimentar incessantemente, é fugir ao controle da representação. Conhecer é construir um mundo e construir-se a si próprio (KASTRUP, 2007).

$\mathrm{Na}$ experimentação vamos, no diálogo com os protagonistas da escola, desenhado e redesenhando mapas curriculares para diferentes aprendizagens, diferentes saberes e diferentes tempos. Do ponto de vista da invenção, a cognição não se limita a um funcionamento regido por leis e princípios invariantes que ocorreriam entre um sujeito e um objeto pré-existentes, entre o eu e o mundo. Ela é uma prática de invenção de regimes cognitivos diversos, co-engendrando, ao mesmo tempo, o si e o mundo, que passam à condição de produtos do processo de invenção (KASTRUP, 2010).

Os encontros de invenção e formação foram realizados durante todo o ano de 2013, com periodicidade quinzenal, buscando criar condições de viabilidade para a construção de propostas para além da flexibilização curricular para alunos surdos com deficiência. Os professores que atuam na educação de surdos, através da interferência de professores e estudantes da Faculdade de Educação da UFRGS, realizaram estudos temáticos, aplicando e 
avaliando alternativas de ensino para alunos surdos com deficiência, para assim criar atividades de promoção do acesso ao conhecimento e a aprendizagem.

As experiências do currículo para surdos com deficiência são constantemente pensadas e fluem no movimento de adaptação e readaptação diária do espaço da escola bilíngue. Os professores, por vezes, se encontram discutindo se as adaptações, se as flexibilizações, se as adequações no currículo foram satisfatórias, sobretudo aquelas que não alcançaram qualquer aluno ou produziram qualquer sinal de sucesso. É um trabalho árduo e diário, exige produzir no cotidiano escolar muitas situações de aprendizagem que sejam adequados e acessíveis a uma maioria e a uma minoria, conjuntamente. Há que se dar em um aluno como no conjunto das turmas a aprendizagem, seja ela complexa, do detalhe, de uma pequena parte do todo. Há que se fazer experiências de aprendizagem no coletivo que também aconteçam individualmente nos alunos. É preciso fazer acontecer experiências de aprendizagem diversas no contexto de sala de aula e no espectro macro da escola. Jorge Larrosa (2002, p. 01) disse que "a experiência é o que nos passa, o que nos acontece, o que nos toca". Mas quando se trata do espaço bilíngue inclusivo, não é fácil encontrar as situações que se tornarão uma experiência para os alunos surdos com deficiência.

Durante um dos encontros de formação dos professores, iniciou-se uma discussão sobre quais alunos surdos com deficiência têm diagnóstico ou quais deles são apenas suspeitas. Veiga-Neto (2002), ao escrever sobre a "desconfiança ocular", nos faz pensar que precisamos ter nosso olhar desconfiado sobre o que muitas vezes é naturalizado na escola. Precisamos ter um olhar diferenciado para o currículo que os professores bilíngues estão desenvolvendo para esses alunos surdos com deficiência. Muitos dos professores conseguem desenvolver esse olhar e outros estão dispostos a inventar um novo olhar para si e para suas práticas, um olhar diferenciado. Para muitos professores saber o diagnóstico do aluno será indicativo para o que ele irá experimentar em diferentes espaços da escola ou para definir qual desses espaços é o mais adequado para cada aluno, conforme vemos no excerto abaixo:

Professor $A^{4}$ : "(...) eu gostaria muito de ver o laudo para ver o que ele tem, ficamos nessa dúvida sem a confirmação de nada. (...) mas sem eu saber o

\footnotetext{
${ }^{4}$ Os professores e seus enunciados estão organizados conforme as letras do alfabeto para melhor compreensão por parte do leitor.
} 
que tem aquele aluno fica difícil. Se não eu acho que ele se dá bem naquela turma, mas não. Levo para outra. Mas também não deu certo. Levo para turma da manhã porque o currículo parece mais próximo a ele, mas também não. Por isso que eu acho importante o laudo. Eu sei que precisamos conhecer o nosso aluno. Mas, por exemplo, se ele é paralisado cerebral e não consegue segurar o lápis (...)".

\begin{abstract}
Professor B: "(...) todos os dias na nossa prática passamos questionando o que podemos fazer, se estamos beneficiando aquele aluno ou não. Às vezes tentamos fazer um trabalho individualmente ou no coletivo. No final do ano podemos beneficiar ainda mais os alunos. OK., por exemplo, quando ele veio para cá, nós não tínhamos a mínima ideia de como trabalhar com ele. Eu não sabia o que ele tinha agregado à surdez, mas continuamos em contato com ele para pensar em adaptações. O tempo todo em planejamento. Muitas vezes recebemos deficientes intelectuais sem diagnóstico, fluentes em Libras, mas que não tem um diagnóstico."
\end{abstract}

Em que medida a indicação, definição em termos diagnósticos clínicos tem otimizado o trabalho do professor? O quanto os professores sentem-se empodeirados para mudar o rumo, propor reinvenções para suas salas de aulas, redesenhar outros currículos? Se o currículo não for pensado para as singularidades, se essa preocupação não existir, como serão organizados os conteúdos, administradas e desenvolvidas as aulas? Ter o conhecimento do diagnóstico pode auxiliar os professores a organizar e pensar propostas para desenvolver o currículo, proporcionando a esses alunos a constituição de identidades surdas de acordo com a especificidade de cada um. Esse processo é reflexo de um currículo vivo, pensado a partir dos indivíduos. Segundo Tomaz-Tadeu (2003, p.204), ao escrever sobre as relações de poder implicadas no currículo:

\footnotetext{
A contenção dos corpos docentes é parte central da experiência educacional e, portanto, do currículo. Constitui um elemento central das relações de poder inscritas na prática cotidiana da sala de aula e do currículo, instituindo, legitimando e reforçando hierarquias sociais e reproduzindo relações de saber e autoridade baseadas em noções desencarnadas e descorporificadas de conhecimento.
}

O currículo, ao ser pensado para os corpos dos alunos surdos com deficiência, desafia os professores bilíngues a trabalhar usando o "cérebro curricular" (CORAZZA, 2012a), pois necessitam transformar o currículo em algo múltiplo e a planejar a didática visual para as 
aulas, o que torna o currículo vivo, corporificado, atualizado, diferenciado e experimentado. Nas palavras da autora, Corazza (2008, p. 6), “trata-se de trabalhar, o tempo inteiro, com as diferenças, de reforçá-las e problematizá-las radicalmente, de enfatizar as suas dinâmicas, de viver todas as suas experiências inquietantes e misteriosas”. Sobre os desafios de trabalhar com as singularidades dos alunos e a visão de aluno que a escola tem, o Professor I diz que é necessário:

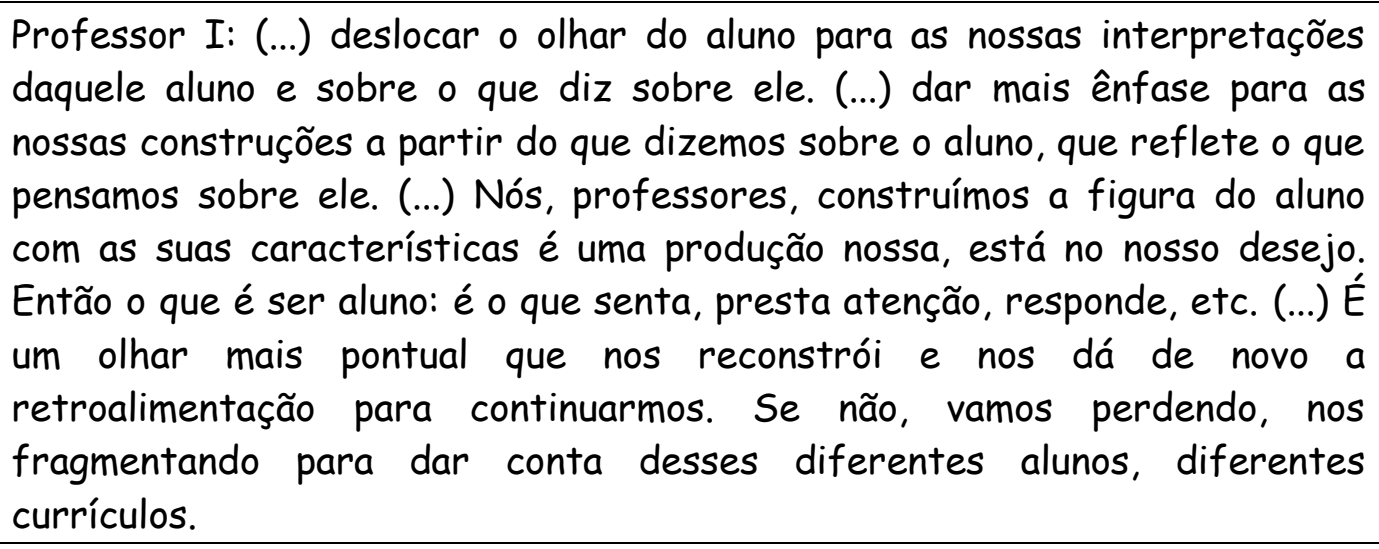
daquele aluno e sobre o que diz sobre ele. (...) dar mais ênfase para as nossas construções a partir do que dizemos sobre o aluno, que reflete o que pensamos sobre ele. (...) Nós, professores, construímos a figura do aluno com as suas características é uma produção nossa, está no nosso desejo. Então o que é ser aluno: é o que senta, presta atenção, responde, etc. (...) É um olhar mais pontual que nos reconstrói $e$ nos dá de novo a retroalimentação para continuarmos. Se não, vamos perdendo, nos fragmentando para dar conta desses diferentes alunos, diferentes currículos.

Podemos perceber que os professores bilíngues estão no processo de (des)treinar o olhar, não mais tentando encontrar em todos os alunos características daquele aluno surdo ideal, para buscar as características e o jeito de ser daquele aluno que está ali e que é diferente, ou seja, o novo olhar sobre os alunos surdos com deficiência. Para isso, buscam subsídios nas pesquisas sobre educação de surdos, mas dificilmente encontram nelas algum respaldo ou pistas para o desenvolvimento do seu trabalho. Eles precisam buscar conhecimentos na área da educação especial, por exemplo: deficiência intelectual, deficiência motora, deficiências múltiplas e deficiência visual.

É preciso ter uma interlocução entre a área de educação de surdos e as diversas áreas da educação especial. Esse diálogo e compartilhamentos em rede podem ser importantes para a qualificação da ação pedagógica do professor, como também para compreensão das demais áreas e deficiências, além dos estudos de outras áreas também sofrerem atualizações e modificações, retirando da deficiência a noção de incapacidade total e pura. Compreender a potência dos corpos que aprendem em meio a experiência da deficiência e em meio a vida, isso é imprescindível reivindicar e implementar na escola, e por parte dos professores. Sobre

Revista Reflexão e Ação, Santa Cruz do Sul, v. 23, n. 3, p. 79-103, Set./Dez. 2015.

http://online.unisc.br/seer/index.php/reflex/index 
a falta de materiais didáticos e a dificuldade que sente em trabalhar com alunos surdos com deficiência, o professor argumenta:

Professor D: (...) Nós temos alguns livros, mas são muito limitados. Agora
tem literatura nova, mas alguns não tem $C D$, alguns são de outro tipo. Não
tem nada prazeroso. Eu vi da Editora Arara Azul, tem CD, mas com vários
textos e sinalização diferente do texto. Os alunos não gostaram. Nós
precisamos de livros digitais produzidos pelo MEC diretamente para o
ensino de surdos. Vejo constantes publicações de livros para ouvintes, mas
sinto falta do material para nós, um material digital de todas as disciplinas,
geografia, matemática, ciências, etc. Todos digitais em Libras fluente.
Precisamos de um material didático para Português, que fosse um CD em
Libras acompanhado do livro didático com frases básicas do que está sendo
sinalizado, em diferentes níveis, acompanhando o nível linguístico da turma.
Essa é a primeira questão. A segunda preocupação é que eu não consigo
ensinar Libras para alunos surdos com deficiência intelectual profunda,
assim como para alunos surdos com baixa visão. É muito difícil. Não tem
material adaptado para ensino de Libras a eles. No Rio [de Janeiro], na LSB
Vídeo, os materiais disponíveis são muito fracos, não aprofundam. Eu vejo
que para os ouvintes têm inúmeros materiais de apoio, mas eu me sinto
limitada para ensiná-los. Busco muitas imagens para explorar o visual deles,
mas não consigo o retorno, eles não se expressam. É muito difícil. Eu não sei
como fazer.

Há uma emergência na produção de materiais que promovam a experiência visual, materiais que potencializem uma perspectiva bilíngue na educação de surdos. Mas também, materiais que, para além das questões da língua, tenham a preocupação com a acessibilidade, com o desenho universal.

Professor D: O mais complicado é que ofereço os materiais e não consigo obter o retorno deles, as respostas. Repito o mesmo diariamente. Prejudica, também, o fato que a disciplina de Libras é uma vez por semana, pois tenho várias turmas para atender. Compreendo que são várias disciplinas que eles precisam ter, mas a Libras fica prejudicada. O que de fato me preocupa é isso, o aluno com deficiência. Quando os outros estão brigando, tenho que parar para dar atenção à briga e depois retomo. Também tenho que chamar a atenção de todos o tempo inteiro, para me olharem. É muito tempo perdido em tão poucas aulas. Então eu tenho uma ideia que parece genial, mas quando 
vou aplicar, não dá certo. Isso me cansa, os surdos com deficiência. Com os surdos normais é tranquilo. As trocas são intensas. Todos os materiais que apresento eles gostam, a Libras flui. O que me preocupa é a política linguística para esses surdos com deficiência.

"Surdos normais": O que isso quer dizer? Segundo Thoma e Kuchenbecker, a "norma surda”, um termo inventado e que circula em escolas de surdos, é uma noção

\begin{abstract}
sustentada pela ideia de que, se for garantido o acesso à língua de sinais e à educação bilíngue, todos os surdos aprenderão na escola. Vemos, então, que a normalização dos surdos, antes sustentada por representações sobre os surdos como deficientes e buscada pelo aprendizado da língua oral e da cultura ouvinte, passa agora a ser buscada pela comunicação em sinais e por fazer de todos os surdos integrantes de comunidades surdas. (THOMA; KUCHENBECKER, 2011, p. 184).
\end{abstract}

Parece que o currículo ouvinte que tradicionalmente é adaptado para os surdos agora está sendo adaptado também para os surdos com deficiências. Não podemos pensar em comparar os alunos surdos com um aluno surdo com deficiência. Os professores precisam reconhecer o perfil de cada aluno com deficiência e desenvolver o planejamento diferenciado que atenda os perfis, focando no potencial de cada um. Os professores da escola bilíngue precisam pensar em estratégias didáticas visuais próprias para esses alunos, pois esse currículo irá gerar múltiplas aprendizagens e compreensões da experiência da surdez. As experiências vivenciadas no espaço da escola irão refletir diretamente nas impressões, aprendizagens, conhecimentos, sensações constituídas pelos estudantes e também pelos professores. Os professores sentem a necessidade de promoção de mais instante de intuição e experimentação, mas justificam que faltam materiais, que precisam conhecer mais sobre as deficiências e também requerem uma adequada e qualificada formação para saber como fazer a inclusão de todos os seus alunos. Também reconhecem que é necessário pensar nas singularidades, como coloca o professor A:

Professor A: O professor precisa ter o olhar diferenciado para cada um dos alunos. Às vezes tu conheces cada um dos alunos, sabe as capacidades deles, então precisas te focar naquele que tu ainda não conhece, a fim de pensar 
em estratégias que revertam essa situação. Muitas vezes tu vais falhar nas
tuas propostas, então reavaliar e planejar uma atividade diferente,
testando cada uma delas. É preciso ter paciência, pois não há modelos
prontos, certezas. A vida do professor tem que ser uma constante busca de
estratégias que venham ao encontro das necessidades dos alunos. E pra isso
tu precisas olhar o teu aluno, perceber como ele é, buscar conhecer o que
ele precisa. Cada aluno tem coisas boas a demonstrar, potencialidades a
desenvolver, mas cabe ao professor perceber isso.

A escola bilíngue para surdos vive suas políticas de inclusão a partir do entendimento do direito a escola, e a aprendizagem de todos os surdos, com ou sem deficiências. A maioria dos professores argumenta que não teve formação para isso. Eles tentam, na medida do possível, desenvolver atividades de acordo com a deficiência do aluno, mas falta preparo para dar conta das questões de acessibilidade e inclusão. Poucos são os professores da escola que fizeram algum curso na área das deficiências, embora alguns tenham feito formação em oficinas de poucas horas. Todos os professores manifestam o desejo em fazer aprofundamento e outros cursos que os auxiliem a desenvolver um trabalho condizente com as especificidades apresentadas pelos alunos que atualmente estudam em suas turmas. É fundamental construirmos redes de apoio para que professores incorporem a discussão da filosofia da diferença para dentro de suas propostas de currículo, suas propostas de ensinagem.

\section{AS POTENCIALIDADES DA ESCOLA E DO CURRÍCULO EM CONTEXTO BILINGUE}

Desde a implementação da LDBEN, em 1996, a Educação Especial e, dentro desta, a Educação de Surdos, vêm ganhando espaços de discussão nas políticas públicas educacionais. Este texto de cunho legal e tantos outros que se constituíram no decorrer dos últimos anos produziram tensionamentos nos movimentos organizados dos surdos, articulados com as escolas e seus educadores, procurando redefinir trajetórias na educação dos surdos.

A Política Nacional de Educação Especial na Perspectiva da Educação Inclusiva (2008), implementada pelo Ministério da Educação, ganha contornos diferenciados, atendendo as demandas e especificidades regionais e locais. Velhos e novos espaços de educação se reconfiguram, levando gestores, educadores e a comunidade surda ao desafio de articular concepções de educação e projetos educativos. A educação de surdos tem se pautado pela perspectiva da diferença cultural e lingüística, marcando uma contraposição com 
discussão das soluções prescritas nas políticas de inclusão a partir de um referencial que passa muito mais pela instrumentalização com intérpretes de libras e constituição de sala de atendimento educacional especializado do que com o reconhecimento da diferença linguística e do direito cultural.

Preferimos, neste projeto, apostar nas mãos que produziam seus próprios enunciados e jeitos de fazer educação, muito mais do que falar ou teorizar sobre. Ter hábito de mudança, de fazer com o próprio corpo com que as coisas do contemporâneo se ajustem, se transmutem, se reconfigurem. "O hábito é, então, o modo no qual um ser (especialmente, o ser humano) "tem" em potência uma técnica, um saber ou uma faculdade, "tem" uma potência de saber e agir." (AGAMBEN, 2009). Parece-nos, então, que é hábito daquele que se compõem na deficiência ou não a potência de agir e mudar. Sem receio de registrar que há crítica ao vivido lá, em atelier. Porém, há também registros fotográficos que registram a memória dos sorrisos. Memórias que são aprendizagens: dos improvisos, das criações, das trocas, do complexo sendo expresso nas molduras, nos vídeos, nos jogos, nos cacarecos que foram levados para os encontros de experimentações.

O grande desafio desses professores era propor e desenvolver o currículo do espaço bilíngue para os alunos surdos com deficiência que ali estão. Para muitos deles a escolha do desafio não foi possível. Eles simplesmente se defrontaram com os alunos surdos com deficiência. A partir de então, veio o desafio de transformar o momento do ensino em aprendizagem expressiva, em estímulos que se tornem em experiência diferenciada na vida de cada um dos alunos.

Como acontece com a maioria dos surdos, os alunos surdos com deficiência também tem pais ouvintes e passam pelo drama de não ter comunicação em casa. Isso faz com que a escola tenha o papel de ensinar a Libras, bem como apresentar a eles conhecimentos de história, de língua, da cultura e da comunidade surda. A educação de surdos tem se pautado pela perspectiva da diferença cultural e lingüística, marcando uma contraposição com discussão das soluções prescritas nas políticas de inclusão a partir de um referencial que passa muito mais pela instrumentalização com intérpretes de Libras e constituição de sala de atendimento educacional especializado do que com o reconhecimento da diferença linguística e do direito cultural. 
Propusemos - de modo justaposto, entrecruzado, consensual, harmonioso - encontros de estudo de currículo que pudessem instrumentalizar os professores e os gestores em suas práticas cotidianas e que isso fosse compondo um outro currículo para a escola. Importante registrar que naqueles "encontros de estudo e pesquisa" participavam em torno de 20 professores e gestores, grande parte deles com formação em educação especial, alguns com proficiência em Libras, outros com formação nas áreas especializadas do currículo.

Sabe-se do número expressivo de alunos surdos com deficiências associadas. Assim como são incluídos em escolas comuns também são encaminhados para escolarização em escolas não bilíngues. Nesta escola, encontravam-se em processo de escolarização alunos com autismo, alunos com deficiência intelectual ou sofrimentos orgânicos que fragilizam suas aprendizagens. Sabe-se também que alunos surdos com ou sem deficiência expressam-se e compõem-se com Libras, experimentando a aprendizagem por meio desta e com esta. Contudo, perguntamo-nos aqueles alunos surdos com deficiência experimentam a aprendizagem com déficits, com fragilidade, com dificuldades pelo não uso da língua? $\mathrm{Ou}$, o que concordamos e procuraremos afirmar aqui: alunos surdos com deficiência requerem aprendizagens diversificadas e uso da cultura visual.

As questões da diferença e da identidade cultural deveriam estar no centro dos debates educacionais, no entanto as políticas públicas, em nome do projeto de inclusão, têm investido na arquitetura de espaços únicos com territórios definidos pela universalização dos corpos e mentes. Num cenário mais amplo, ganham visibilidade grupos sociais e culturais que reivindicam o direito à afirmação de sua identidade e o respeito à sua diferença.

A pedagogia da diferença fala de um Outro constituído na trama de sua identidade e, por não haver apenas um traço identitário, não há argumentação que justifique dizer: que determinado sujeito se constitui pela ou a partir da sua deficiência, estabelecendo assim um único espaço pedagógico capaz de oferecer-lhe o acesso ao conhecimento e aos bens culturais. O Outro, numa sociedade em que a identidade torna-se, cada vez mais, difusa e descentrada, expressa-se por meio de muitas dimensões. $O$ outro é o outro gênero, o outro é a outra sexualidade, o outro é a outra raça, o outro é a outra nacionalidade, o outro é o corpo diferente, e é tudo isso junto combinado com suas histórias de vida.

Nesta perspectiva tem-se tencionado discussões para re-inventar currículos que rompam com a lógica da normalização e que permitam possibilidades de diferentes 
aprendizagens. Este movimento se intensifica nas proposições de alternativas curriculares para alunos com deficiências intelectuais, situação vivenciada nas escolas de educação de surdos. Currículos que movimentam os tempos e os espaços da escola, que se propõem em experimentações de fazeres, seguindo a perspectiva das possibilidades de encontro de saberes, assim como nos propõem Tomaz-Tadeu "e se o currículo (...), fosse concebido como um encontro, uma composição? Isso não mudaria tudo? (2002, p. 55)".

O ensinar que se propõe emancipatório tem na prática da liberdade uma relação contrária à síntese, à totalização, à generalização. A amizade no ensinar e aprender consiste em estar inquieto pelo mesmo. $\mathrm{O}$ mesmo que não se traduz na forma única do saber. $\mathrm{O}$ mesmo que motiva, que desacomoda, que escreve seu texto, que compartilha sua leitura, que redescobre o prazer e que se desafoga do erro. Uma pedagogia emancipatória pressupõe diálogos solidários com a comunidade.

Diálogos que se entrecruzam nos debates políticos em movimentos de cidadania, do conhecimento cultural, significando o conhecimento escolarizado. Uma escola que, nas palavras de Santos (1995), revaloriza "o princípio da comunidade e, com ele, a ideia da autonomia e a ideia da solidariedade" (p. 278) e, ainda, em que "cultura e renascimento cultural constituem, por excelência, a pedagogia da emancipação" (ibidem).

Neste sentido, é reafirmada a concepção de currículo como produtor de diferenças e identidades, que também se constitui a partir de uma rede discursiva permeada por relações de poder. Tanto a escola comum como a escola de surdos possuem dispositivos capazes de colocar este poder em funcionamento. Moraes e Lunardi-Lazzarin (2009, p. 23) destacam que:

\footnotetext{
A Pedagogia surda vem atrelada a práticas de subjetivação, à desconstrução, ao estranhamento de discursos ouvintistas sobre se surdo. Ao falar-se de um currículo surdo, isso não significa silenciar todas as diferenças ou reduzidos surdos a um único "modelo", mas sim mostrar que estes sujeitos constroem uma historicização, estando constantemente em processo de mudança e transformação.
}

E por isso, torna-se extremamente excludente a promulgação de políticas educacionais alicerçadas em verdades absolutas. Tomar o conceito de inclusão como permanência em territórios únicos, em escolas normalizadas, que permitem a diversidade, mas que normalizam a diferença, formalizando em horários específicos a língua de sinais sob a gerência de 
constante interpretação, sem intensidade, na justificativa de que vivemos em um país de falantes da língua portuguesa.

Nomear o que fazemos em educação é mais do que simplesmente empregar palavras. As lutas pelos significados e pelo controle das palavras, a imposição de certas palavras compreende um jogo mais do que as palavras falam. Capturar e regular o estrangeiro tranquiliza a escola, acalma as diferenças e mantêm o corpo curricular precioso dos saberes de verdade. Uma pedagogia da experimentação pressupõe despojamento dos educadores do conhecimento normativo das suas cartilhas de formação, abandono da tutela do saber e promoção de ações protagonistas do ensinar na ética da solidariedade humana. Uma solidariedade de encontro com saberes distintos, tempos e jeitos de aprender. Tomaz-Tadeu (2002, p. 54) nos remete a efeito do que e como os encontros nos afetam:

Que efeitos um corpo tem sobre outro. Quando dois corpos se encontram, de que forma um afecta o outro? Ao encontrar-se com outro, um corpo tem sua capacidade de agir em oposição a sofrer passivamente uma ação exterior - aumentada ou diminuída? A potência de agir. É esse o critério para determinar se um encontro é bom ou não.

\section{AS ENTRADAS, AS SAÍDAS E AS INFINITAS FORMAS DE REINVENÇÕES CURRICULARES}

Os currículos são encontros de movimentos, entradas e saídas para novos acontecimentos, outros percursos para outras formas de existência, "incidências sobre inéditas possibilidades de viver" (CORAZZA, 2012b, p. 02). E assim, vamos de forma viva reinventando os lugares e jeitos do currículo existir, nossa aposta tem sido em transformar o máximo as experiências chamadas de extracurriculares e tempos do currículo formal. E Corazza (2012a, p.02) nos ajuda muito a fazer experimentações quando afirma que "não há um currículo, que não abale as próprias representações, arrastando-se até os seus limites, avesso ou fora. Não há currículo que produza só invariantes. Não há um, que se repita, sem o fazer diferentemente".

E assim, junto com professores estamos criando possibilidades de estar na escola com um pouco de prazer ou com o máximo de experiências alegres, curiosas, provocativas. Temos, no contexto da educação de surdos e em escola bilíngue, uma grande vantagem: os alunos 
querem a escola, pelo simples fato dela existir e nela encontrar uma língua de significados, língua que permite e que cria possibilidade de encontros. Então, nos desafiar a construir propostas pedagógicas que tencionem a norma do disciplinamento das áreas, com a definição das cargas horárias, impondo valoração e peso de importância, se torna muito possível.

\footnotetext{
Não há currículo que não acabe se distanciando da ciência oficial e do aparelho de Estado, em seus consensos sobre estratos, classes, espécies, modelos. Nenhum, que não redistribua os dados, force novos lances, relance teses alegres e livres. Não há currículo que não considere a realidade, senão como interpretativa ou perspectivista. Nenhum, que não minorize currículos majoritários, calcados na opinião e no senso comum. Não há currículo que apenas aplique a teoria à prática ou vice-versa. Nenhum, que se contente com o vazio da compreensão especulativa. Não há currículo que não tenha intuições. Nenhum, que não crie ilusões, as quais não são contrassensos abstratos, nem somente pressões de fora, mas miragens do pensamento. Não há currículo que ignore que grande parte das coisas não merece ser dita nem escrita. Nenhum, que não ria, especialmente de si mesmo. Não há currículo que não sofra as vicissitudes de sua concepção, os devires de sua gestação e as dores do seu vir à luz. Nenhum que não saiba que vai morrer e que outros currículos advirão justamente da sua morte. (CORAZZA, 2012a, p. 02-03).
}

A morte de um currículo cria possibilidades novas que necessariamente não serão melhores ou piores que as anteriores. Mas, mesmo assim são nascimentos para outras descobertas. A proposta escolar de tencionar currículos de emancipação não se esgota no esforço da conscientização, traduzida por alguns como uma velharia suburbana, ela se renova no sonho, na utopia, na denúncia e no anúncio. Sem todos esses ingredientes, somados ao prazer e ao desejo, só nos resta o treinamento técnico na normalização de mentes rápidas em um tempo da diferença traduzida nos sentimentos de tolerância.

A escola que constitui um empreendimento humano, uma organização histórica, política e culturalmente marcada, deve ser entendida como um território em que indivíduos e grupos de diferentes interesses, preferências, crenças, valores e percepções da realidade mobilizam poderes e elaboram processos de negociação, pactos e enfrentamentos. No entanto, quando a escola mantém a na lógica normalizadora toma para si e elege padrões culturais, passando, através do seu currículo, capturar os estrangeiros a essa cultura. São tentativas seculares que fracassam na 'sobrevivência' das culturas 'periféricas' mantidas vivas nos corredores e pátios da escola. Se o processo de significação girasse sempre em torno dos mesmos significados e se os mesmos significados fossem fixos, e se as marcas linguísticas 
que utilizamos estivessem vinculadas a significados evidentes, não haveria ações de significação. As lutas por significado não se resolvem no terreno epistemológico, mas no terreno político, no terreno das relações de poder.

Despolitizando a educação e reduzindo-a aos discursos vencidos das práticas disciplinadoras, a escola se mantém enclausurada em saberem instituídos pelas verdades da repetição. A educação como ato político fala das tramas do cotidiano, dos desejos de pertencimento, das estratégias de sobrevivência cultural. Sentidos que dão vida e criam espaços para os jogos dos saberes da escola.

Compreender como ato de cidadania estar na escola é muito mais do que frequentar suas turmas, avançar no conteúdo e receber o diploma de conclusão. Estar na escola é cidadania na medida em que o texto da escola dialogue com propostas de gabinetes e gerenciamentos das políticas oficiais. Prestar atenção ao que dizem os movimentos sociais, ao que pedem seus alunos, é tarefa imprescindível de um gestor educacional que se predispõem a assumir o princípio básico constitucional da democracia.

Uma teoria do currículo deveria discutir algumas questões centrais: a questão do conhecimento e da verdade; a questão do sujeito e da subjetividade; a questão do poder; a questão dos valores (CORAZZA e TOMAZ-TADEU, 2003). Mas, afinal, o que compõe um currículo? O mais fácil de concluir e argumentar é a questão do conhecimento e da verdade, supondo-se que isto é o primordial e o que deve ser ensinado e prescrito no currículo escolar. Contudo, os sujeitos e a subjetivação não podem ser ignorados em sua potência e importância na composição do currículo escolar. Afinal, "todo currículo quer modificar alguma coisa em alguém, o que supõe, por sua vez, alguma concepção do que é esse alguém que deve ser modificado".

\footnotetext{
Ao conceber um currículo, queremos que alguém passe a respeitar as leis de trânsito, modifique sua atitude em relação à prevenção da Aids, torne-se uma cidadã exemplar, transforme-se em uma trabalhadora produtiva. Da mesma forma, há uma série de pressupostos sobre a matéria sobre a qual essas transformações se darão: processos mais ou menos conscientes; matéria mais ou menos plástica; participação mais ou menos ativa; efeitos de menor ou maior duração. Ou seja, todo currículo carrega, implicitamente, alguma noção de subjetivação e de sujeito: quem nós queremos que eles e elas se tornem? o que eles e elas são? (CORAZZA e TOMAZTADEU, 2003, p. 38).
} 
Conforme o autor citado, o currículo e a educação "podem ser concebidos como uma arte do encontro e da composição, na qual o que importa não é a forma e a substância, o sujeito ou o objeto, mas o que se passa entre os diferentes corpos que habitam um currículo" (Ibidem, p.43). Não há currículo que não expresse ou não viva uma vida, ele precisa trabalhar em prol da afirmação da vida. "Os corpos distinguem-se entre si pelo movimento e pelo repouso, pela velocidade e pela lentidão e não pela substância”, declara Spinoza na Ética.

Do que percebemos em educação, de um modo geral, um currículo é constituído por saberes, e um professor normalmente está preocupado em como fazer uso desse currículo, como fazer com que esses saberes cheguem ao outro e produza efeitos para transformá-lo. Poderíamos começar por imaginar que coisas, que desejos, que vontades, as mais heterogêneas, as mais indisciplinadas, "as mais improváveis (sorvete flambado com suspiro), se encontram e se combinam no currículo" (TOMAZ-TADEU, 2002, p. 55).

$\mathrm{Na}$ educação de surdos pulsa o desejo do encontro. O encontro com uma língua de significação que se traduz na potência de querer estar na escola, e este é o recurso precioso que devemos aproveitar. Debruçar-nos na tarefa de compreender maneiras para oferecer condições para pensar, perceber, sentir, avaliar, afetar um currículo, de maneira vívida. Professores precisam se lançar em desafios, não só pensando na aprendizagem dos seus alunos, mas também no seu prazer em dar aula, em estar instigado pela invenção da sua própria aula. Para fugir da essencialização sobre como organizar e prescrever o currículo sugerimos privilegiar algumas problematizações e aberturas para pensar acerca do mesmo:

\footnotetext{
Quem quer? Quem é aquele que quer? O que quer aquele que diz? Quais são as forças que dominam aquele que quer isso? Qual a vontade que possui aquele que quer isso? Quem, então, se exprime e, ao mesmo tempo, se oculta naquele que quer isso? Qual o seu tipo, isto é: a vontade, a força, o lugar e a ocasião em que ele quer? Quem ou de qual ponto de vista quer isso? Esta vontade de poder (este 'quem'?) supõe o quê? Qual a imagem do pensamento pressuposta por esse tipo, que não é um indivíduo, mas aquele que quer a vontade de? O que quer aquele (tipo) que diz, pensa, sente ou experimenta isso? O que quer aquele que não poderia dizer, pensar, sentir ou experimentar isso, se não tivesse tal vontade, tais forças, tal maneira de ser? 2) Quando quer? Em que condições? Em que caso(s)? 3) Onde quer? Lugares? circunstâncias? pontos de vista? 4) Como quer? Por quais operações? por quais configurações de forças? 5) Quanto quer? Intensidade das forças que querem isso? Extensão da vontade que quer isso? (CORAZZA, 2012a, p. 11-12).
} 
Pensar os currículos possíveis na educação de surdos, que privilegiem o estudo de conceitos como objetos de estudo e aprendizagem, pode favorecer a produção movente de conhecimento e subjetivação. Tantos modos de pensar os currículos, modos de pensar diferente o currículo. Um currículo que se move quando articula produção de saberes e processos de subjetivação desde as variadas formas, pela labilidade das formas.

Propor ações de extensão e pesquisa entre escola e universidade promove mecanismos de formação constante, tanto para professores quanto para alunos em formação. Propomos com estas formações de professores em educação de surdos ampliar o debate para além da garantia do reconhecimento cultural e linguístico da surdez, condição indiscutível. Precisamos centrar nossas intenções na articulação de propostas pedagógicas e de desenhos curriculares que desafiem as normas da dicotomia ensino aprendizagem. Precisamos nos propor para releituras, para novas organizações territoriais, a menos disciplinamento de corpos e mentes (GIORDANI, 2010).

Pensar na diferença dentro da diferença compõem o eixo de trabalho, propor currículos em educação de surdos, é pensar que não há modelo surdo. Propor uma educação bilíngue não garante que todos os alunos irão dominar as estratégias de uso das línguas em questão, inclusive de sua língua nativa (língua de sinais). Neste sentido, é fundamental ao propor espaços de escolarização que o desafio seja perceber o aluno na sua individualidade sem nunca perder a disponibilidade de estar com ele na construção de saberes, independente a lista conteúdos a serem cumpridos. O que vale é nunca esquecermos que, como professores, também estamos em constante aprendizagem e mudança. Só desta forma estaremos prontos para novos encontros. Encontros com nossa tarefa de intercessores do conhecimento e com as múltiplas possibilidades de inventar e re-inventar currículos na escola.

Considera-se importante neste projeto os estudos relacionados aos diferentes currículos, necessários para a promoção da aprendizagem por parte de qualquer estudante. Em geral, os professores, individualmente, constroem as entradas de seus alunos ao currículo. Cada professor inventa formas de inserir conteúdos e formas de expressão no currículo. Afirmamos, sim, que "o professor se faz em sua didática" (NOAL-GAI, 2014, p. 07). Um modo de fazer aulas, de imprimir ideias e sensações, de ensinar e contaminar, faz outros aprenderem pela alteridade do que se ensina. Provocar aprender é se misturar pela contaminação pela alteridade pela multiplicidade. Provo - conceitos, conteúdos, informações, 
dados, gráficos, jogos, lógicas, genes, fórmulas - pela boca que fofoca, cochicha, conta, causa, sorri daquilo que ensina.

Não se pode afirmar que o currículo é cópia ou reprodução de outros currículos. Nesta pesquisa encontramos diferentes currículos sendo produzido por diferentes professores. Também produzimos, por meio de ateliers, outros tantos modos de entrar em conteúdos e fomentar aprendizagens e conhecimentos. Ou seja, produzimos junto a professores currículos que tenham vinculação com singularidades: de escolas, de contextos, de desejos, de professores e alunos.

Neste texto desenvolveu-se a descrição de alguns currículos inventados, não necessariamente implementados, ao longo de encontros de formação de professores e gestores em escola de surdos da rede municipal de ensino de Porto Alegre. Com proposição de atelier pedagógico, os encontros de formação de professores, como comumente se diz, traçaram-se pontos relevantes para a potencialização da aprendizagem de alunos surdos com ou sem deficiência como de outros estudantes, em tempos de multiconexão, transinteração e de cultura visual. Os ateliers serviram para que afirmássemos uma cultura visual bilíngue.

\title{
CHARTING CURRICULUM ON DEAF EDUCATION: KNOWLEDGE AND PRACTICES BETWEEN TEACHERS-DIFFERENCES
}

\begin{abstract}
This text was constructed from the description of some curricula produced over teacher training meetings and managers in school for the deaf in the municipal Porto Alegre teaching. With pedagogical Atelier proposition, training meetings produced movements among teachers, both in discussion about learning deaf students with or without disabilities. It was proposed tasks, experiments, discussions, views that claim different times Multiconnection of transinteração, visual culture. The workshops served to assert a visual culture differences between bilingual, with the full right of defense to school and their ensinagens by all deaf students. The script that we present here is the result of analyzes from the teacher training meetings and the trial resumes, these materials make up part of the research activities "Mapping the education of deaf students with disabilities: different learning and different
\end{abstract}


GIORDANI, L. F.; GAI, D. N.; MARINS, C. L.

knowledge," coordinated by teachers Daniele Noal Gai and Liliane Ferrari Giordani and research "Construction Processes and Curriculum Development for the Deaf with Disabilities in a Bilingual School for the Deaf", developed by graduate student Cassia Lobato Marins. Throughout this text we devote ourselves to think in collective buildings for learning curriculum in a school who propose bilingual since they describe actions that affirm the education and learning of deaf students with disabilities promoted amid a visual culture.

Keywords: Deaf Education; Curriculum; Cartography; Disability

\title{
MAPEANDO CURRÍCULOS PARA LA EDUCACIÓN DE SORDOS: CONOCIMIENTOS Y PRÁCTICAS DOCENTES
}

\begin{abstract}
Resumen
Este texto fue construido a partir de la descripción de algunos planes de estudio producido más reuniones de formación de profesores y administradores en la escuela para sordos en la enseñanza municipal de Porto Alegre. Con pedagógica propuesta de Atelier, reuniones de capacitación producen movimientos entre los profesores, tanto en la discusión sobre el aprendizaje de los estudiantes sordos, con o sin discapacidad. Se propuso tareas, experimentos, debates, opiniones que dicen diferentes momentos multiconexión de transinteração, la cultura visual. Los talleres sirvieron para afirmásemos unos visuales diferencias culturales entre bilingüe, con el pleno derecho de la defensa a la escuela y sus ensinagens por todos los estudiantes sordos. La secuencia de comandos que presentamos aquí es el resultado de los análisis de las reuniones de formación del profesorado y el juicio se reanuda, estos materiales forman parte de las actividades de investigación "Mapeo de la educación de los alumnos sordos con discapacidad: de aprendizaje diferente y conocimientos diferentes", coordinado por profesores Daniele Noal Gai y Liliane Ferrari Giordani y de investigación "Procesos de Construcción y Desarrollo Curricular para Sordos con discapacidad en una escuela bilingüe para sordos", desarrollado por el estudiante graduado Cassia Lobato Marins. A lo largo de este texto nos dedicamos a pensar en los edificios colectivos para el aprendizaje curricular en una escuela que proponen bilingüe ya que
\end{abstract}


CARTOGRAFANDO CURRÍCULOS NA EDUCAÇÃO DE SURDOS: SABERES E PRÁTICAS DOCENTES ENTREDIFERENÇAS

describen acciones que afirman la educación y el aprendizaje de los alumnos sordos con discapacidades promovidas en medio de una cultura visual.

Palabras clave: Educación para sordos; Plan de estudios; Cartografía; Discapacidad

\section{REFERÊNCIAS}

AGAMBEN, Giorgio. O que é o contemporâneo e outras coisas. Chapecó: Argos, 2009.

CORAZZA, Sandra. O drama do currículo: pesquisa e vitalismo de criação. IX ANPED SUL, 2012a. Disponível em:

http://www.ucs.br/etc/conferencias/index.php/anpedsul/9anpedsul/paper/viewFile/128/78. Acesso em 02 de Mar. $/ 2013$.

. Currículo da infância e infância do currículo: uma questão de imagem. In: X Colóquio Luso-Brasileiro sobre Questões Curriculares \& VI Colóquio Luso-Brasileiro de Currículo: desafios contemporâneos no campo do currículo. Subtema: Currículo e educação infantil. Belo Horizonte: 4 a 6 setembro 2012. (Texto dig.). Porto Alegre: 2012b.

Currículo na Contemporaneidade. Conferência Formação Continuada: UNIFEBE (Brusque) e FURB (Blumenau) Brusque, Blumenau, SC, 21, 22 de julho de 2008. Disponível em:

http://www.unifebe.edu.br/04_proeng/formacao_continuada/2008_2/material_palestras/curric ulo_na_contemporaneidade.pdf. Acessado em: 03 Nov. de 2015.

CORAZZA, Sandra; TADEU, Tomaz. Composições. Belo Horizonte: Autêntica, 2003.

DELEUZE, Gilles. Diferença e Repetição. Trad. Luiz B. L. Orlandi; Roberto Machado. Rio de Janeiro: Graal, 2006.

GIORDANI, Liliane. Educação inclusiva na educação de surdos: o que se permite entre a política oficial e o movimento social. Santa Cruz do Sul:EDUNISC, 2010.

KASTRUP, Virginia. A invenção de si e do mundo: uma introdução do tempo e do coletivo no estudo da cognição. Belo Horizonte: Autêntica, 2007.

. O funcionamento da atenção no trabalho do cartógrafo. In PASSOS, Eduardo;

KASTRUP, Virginia, ESCÓSSIA, Liliana (orgs) Pistas do Método da Cartografia. Porto Alegre: Sulina, 2010. 
GIORDANI, L. F.; GAI, D. N.; MARINS, C. L.

LARROSA, Jorge. Notas sobre a experiência e o saber da experiência. Rio de Janeiro Revista Brasileira de Educação, nº19 Jan./Apr. 2002.

MORAES, Mônica; LUNARDI-LAZZARIN, Márcia. Pedagogia e diferença: capturas e resistências nos discursos curriculares da educação de surdos. In THOMA, Adriana; KLEIN, Madalena. Currículo e Avaliação: a diferença surda na escola. Santa Cruz do Sul: EDUNISC, 2009. Pag16 -31.

MINISTÉRIO DA EDUCAÇÃO. Lei de Diretrizes e Bases Nacionais. MEC, Brasil, Brasília, 1996.

MINISTÉRIO DA EDUCAÇÃO. Política Nacional de Educação Especial na Perspectiva da Educação Inclusiva. MEC, Brasil, Brasília, 2008.

NOAL-GAI, Daniele. Ética do Brincar. Projeto de Tese. Faculdade de Educação.

Universidade Federal do Rio Grande do Sul. Programa de pós-graduação em Educação. Linha Educação em Saúde. 2014.

SANTOS, Boaventura de Souza. Pela mão de Alice: o social e o político na pós-modernidade. São Paulo: Cortez, 1995.

Secretaria Municipal de Educação. Cadernos pedagógicos: ciclos de formação. Porto Alegre: SMED, 1999.

TADEU, Tomaz. A arte do encontro e da composição: Spinoza + Currículo + Deleuze. Revista Educação \& Realidade. Vol 27, nº 2, jul./dez.2002. Disponível em: http://seer.ufrgs.br/educacaoerealidade/article/view/25915/15184. Acesso: 28/06/2013.

SKLIAR, Carlos. Incluir as diferenças? Sobre um problema mal formulado e uma realidade insuportável. In: Revista Artes de Educar. Volume 1, Número 1. UERJ: 2015.

SPINOZA, Baruch. Ética. Belo Horizonte: Autêntica Editora, 2011.

THOMA, Adriana; KUCHENBECKER, Liege. Processos de In/Exclusão de Surdos Down em uma Escola de Surdos. In: THOMA; Adriana da Silva; HILLESHEIM, Betina. (Org.). Politicas de Inclusão: gerenciando riscos e governando as diferenças. Santa Cruz do Sul: EDUNISC, 2011, p. 179-197.

VEIGA-NETO, Alfredo. Olhares. In COSTA, Marisa. Caminhos investigativos: na pesquisa em educação. Rio de Janeiro: DP\&A, 2002, p-23-38.

Data de recebimento: $17 / 05 / 2015$

Data de aceite: $25 / 08 / 2015$ 